\title{
Enhancements
}

\section{How and Why to Become Better, How and Why to Become Good}

\author{
VOJIN RAKIĆ
}

Enhancement is not a novel idea in the history of human thought. Icarus is reported to have wished to become more powerful than God planned humans to be, and Goethe`s Faustus went even so far as to conspire with Satan in order to obtain the wisdom God did not envision for humans. Both Icarus and Faustus paid a high price for their ambition: death in the case of Icarus and disappointment in what Satan was able to offer, madness, and self-annulment in the case of Faustus. Should we fear that human enhancement will condemn us to the same fate as Icarus and Faustus? And if we have reasons to fear, might moral enhancement be a solution?

This special section of Cambridge Quarterly of Healthcare Ethics entitled "Enhancement and Goodness" deals with the issue of enhancement, with a special focus on moral enhancement.

The power that the idea of moral enchancement holds over us is captured in the lengendary tale of Sheherezade, storyteller extraordinaire, and King Shahryar of Persia. ${ }^{1}$ In Richard Burton's classic translation, the king had a cruel and ruthless history of ordering his vizier to bring him a virgin for the night only to have her beheaded in the morning. When the vizier could find no more virgins, he knew the wrath of the king would result in his death. In order to save the vizier, who was her father, Sheherazade volunteered herself to the king. During the night, Sheherezade began telling the vile sociopath a story that-by designshe did not finish by dawn. King Shahryar became intrigued by how the narrative would end, and ordered her to complete the story the next night. She finished that story, but started another only to leave that one also unfinished by dawn. The king, engrossed in the tale, delayed her execution for another day. The next night it was the same and this pattern continued as Scheherazade's gift for storytelling touched the king's heart, eventually causing him to repent his previous atrocities. Now filled with, love and piety, he married Sheherazade. Shahryar became a better man. The 1001 nights Sheherezade spent with him made this possible. They led to Shahryar's moral enhancement. Sheherezade used a combination of cognitive and moral enhancement to change Shahryar: she taught him

This issue largely assembles contributions based on versions of papers presented at the conference "Enhancing Understanding of Enhancement," organized by the Center for the Study of Bioethics, in collaboration with The Hastings Center, on October 27 and 28, 2015 in Belgrade, Serbia.

John Harris, who is jointly responsible for this volume as a guest editor, was unfortunately hospitalized for an extensive period in 2016 and was not able to contribute to this introduction. He is now fully recovered. 
about morality in order to make him understand where he went wrong and at the same time she motivated him by his love for her to make a better man of him.

In addition to a common literary theme, the aspiration to become a better person appears to have been one of the greatest preoccupations and passions throughout cultures. Not surprisingly, a lot has been written on the subject of how to morally enhance ourselves: sacred and secular texts written in the Jewish, Christian, Islamic, and other traditions being some of the most influential manuscripts on moral enhancement in human history.

A similar question, "How to be good?"2 might even have received less attention than the question of how to become better. A possible reason is that it is common for people to believe that they know how to be good, but do not think they act in accordance with that knowledge. Hence, they ask the question how to become better; that is, how to bring their actual behavior into line with their knowledge of what it means to be good.

The case can be made that humanity, in spite of all its efforts, has failed miserably in morally enhancing itself throughout its history. Some successes have occurred: slavery has been abolished in its most blatant forms in much of the world, the number of liberal states has been on the increase in the last two centuries, ${ }^{3}$ and the history of humanity arguably shows a steady decrease in violence. ${ }^{4}$ These successes are, however, meager ones for a time span of several millennia, a span after which the world still sees horrendous injustices, cruelties, and suffering. An essential (but not the only) reason for this scanty record is that humans, although generally aware of their failings, have proven incapable of bridging the comprehension/motivation gap: the gap between how they believe it is morally right to act and how they actually act.

Apart from the gap between knowing the good and being good, moral enhancement also refers to humans' better understanding of what it means to be good. Hence, the cognitive element in moral enhancement is also essential. Moral enhancement is both about cognition and motivation. Moral enhancement can both help humans understand how to be good and motivate them to bridge the gap between knowing the good and doing good. Moral enhancement refers, therefore, to a better understanding of goodness and to a successful application of this understanding. In that sense it is a discourse on becoming better.

Can new biotechnologies give some new hope for humankind in this respect? Do they open up the possibility of humanity becoming better in ways it has not been capable of until now? Can they help humans bridge the great gap of their moral existence? What is the relationship between moral enhancement and other enhancements? How do we actually understand enhancement and how can we enhance our understanding of enhancement such as how to and why to be good? These are some of the central questions being raised in this collection of articles. Formulated succinctly, it is a collection that addresses from a variety of perspectives the issues of enhancement, goodness, and their relationship. It deals with the question of how and why to enhance ourselves, morally and otherwise.

Michael Hauskeller's article carries the title "Is It Desirable to Be Able to Do the Undesirable? Moral Enhancement and the Little Alex Problem." Hauskeller problematizes the relationship between moral enhancement and freedom. He argues that it is difficult to see how a world in which there is no moral evil (e.g., one that has been brought about by compulsory moral bioenhancement) can be regarded as worse than a world in which people are not only free to do evil, but where they 
actually do it. If we adopted such a view we would, under certain circumstances, believe that the bad can be better than the good. In spite of this paradoxical consequence, Hauskeller defends that view. He also argues that the strained relationship between moral enhancement and freedom affects both compulsory and voluntary moral enhancement. Hauskeller apparently does not attach value to the argument that in the case of voluntary moral bioenhancement, giving up one's freedom to act in a morally inappropriate way need not be permanent. We can imagine voluntarily morally bioenhanced people who opt to switch back to their initial condition; something that ongoing compulsory moral bioenhancement programs make impossible by default.

In her commentary on Hauskeller, Sarah Chan criticizes his attempt to define freedom to be good entirely on our own terms and no one else's. Such an attempt brought Hauskeller to equalize voluntary and compulsory moral enhancement, as the former allegedly makes us slaves to our prior selves. Hauskeller's line of reasoning does not make sense, argues Chan, as our concept of "the good" is itself something that is determined in ways beyond our control. Hence, it can never be defined solely on our own terms.

In my article "Moral Bioenhancement and Free Will: Continuing the Debate," I elaborate on issues of moral bioenhancement and free will. I expand on my differences with Ingmar Persson and Julian Savulescu. Persson and Savulescu have criticized my conception of voluntary moral bioenhancement. One of their central claims was that it ignores the extent to which freedom is a matter of degree. I argue that freedom as a political concept, or one that is analogous to a political concept is scalar in nature, but that freedom of the will is a threshold concept. I show that a limitation of this type of freedom to will amounts to a limitation on our freedom to think; however, even if the dogma that denies the existence of a free will were true, I show that such an illusion of free will is one that ought to be cherished, as it is essential to our human identity and to morally responsible behavior. I proceed by adding three further arguments against compulsory moral bioenhancement. First, compulsory moral bioenhancement radicalizes the relationship between moral ends and means to such an extent that it might render the very idea of moral enhancement absurd; second, a program of compulsory moral bioenhancement faces the difficulty of who/what is supposed to develop and run it; and third, the consequence of compulsory moral bioenhancement might be political repression.

In response, James Hughes agrees with my argument against Persson and Savulescu in that he also considers voluntary moral enhancement to be the most desirable option. Unlike me, however, Hughes is not inclined to ground his argument in the issue of free will. Accepting as a material fact the dogma that free will is an illusion, Hughes develops his line of thought in a different direction than I do, leaving aside my contention that neither the option of free will being reality nor the option of it being an illusion can justify the idea of subjecting the entire population to compulsory moral bioenhancement.

Harris Wiseman's article is entitled: “Would We Even Know Moral Bioenhancement If We Saw It?" Wiseman is critical of the idea of moral bioenhancement. He argues that this idea conceals a plurality of meanings. In Wiseman's account, morality is frequently approached in a dichotomous manner. Wiseman focuses in his article on three dichotomies pertaining to moral enhancement: "cognitive versus emotional," "voluntary versus compulsory," and "positive versus remedial." Although the 
cognition/emotion dichotomy does have limited use in describing extreme cases, on the whole it is a particularly distorting split that, in Wiseman's judgment, ought to be strongly de-emphasized or even removed from the discourse. Similarly, the distinction compulsory-voluntary is not always a clear-cut one. Furthermore, moral bioenhancement can be both radical and remedial. In the former case it is to be applied "across the board," whereas in the latter case candidates for moral enhancement would be those with serious moral weaknesses (e.g., people with sociopathological personality disorders). Hence, the whole debate on moral enhancement ought to be conducted within a specified context. Wiseman also draws a distinction between "hard" and "soft" moral enhancement. The latter already exists, although we sometimes do not recognize examples of it. According to Wiseman, my concept of incentivizing moral enhancement is such an example.

Robert Sparrow's commentary is critical of Wiseman's tendency to overextend the meaning of the term "moral bioenhancement." Wiseman believes that state incentivized moral bioenhancement already exists, and denotes it by the term "soft moral bioenhancement." Sparrow, on the other hand, argues that it is a mistake to treat this and other "forms of state paternalism" as moral bioenhancement, preferring instead to stick to the usual terminology.

In their article "Evaluating Moral Bioenhancement: Drawing Inspiration from Forensic Psychiatric Practices, Moral Education, and Public Health Ethics," Maartje Schermer and Jona Specker make an attempt to approach the debate on moral enhancement in a less abstract fashion than they believe is frequently the case in existing literature. They ask which ethical considerations are appropriate to evaluate moral enhancement interventions in a set of existing practices. They refer to debates on the proper scope of moral education, proposals for identifying early risk factors for antisocial behavior, and, finally, the challenges of balancing individual freedom and third party concerns in (forensic) psychiatry. Ethical considerations from the latter domain may be relevant when considering whether moral enhancement interventions ought to be compulsory, but only in that domain. Given all the highly diverse domains in which moral enhancement operates, Schermer and Specker argue that we should not expect to encounter a single well-defined set of practices that ought to be denoted by "moral bioenhancement."

Bert Gordijn analyzes the attempt of Jona Specker and Maartje Schermer to inform and add to current debates on moral bioenhancement by focusing on moral education, screening for risk factors for antisocial behavior, and forensic psychiatry. According to Gordijn, the ethical considerations within these three practices that the authors advance as helpful in the discussion about moral bioenhancement are in fact not of much use. Although Specker and Schermer tried to approach the debate on moral enhancement in a more concrete fashion, Gordijn believes that their argument remains abstract.

In their contribution "Containing Multitudes: Moral Enhancement, Game Theory, and the Stability of Society" Anders Sandberg and João Lourenço de Araujo Fabiano argue that "social value orientation" (the way individuals evaluate the relationship between their own and other's payoffs) might be a target of future moral enhancers. The decisions we make when we establish social relationships often deal with conflicts between the individual and society, which can be referred to as "social dilemmas." Sandberg and Fabiano simulate a moral enhancement model in which agents play games with each other with the possibility of enhancing their social value orientations based on maximizing personal satisfaction. They find that the 
balance between prosociality and individual compensation-maximization is affected by different morally relevant factors. Hence, moral enhancement considerations should take issues of social emergence into account.

Soren Holm's analysis of Fabiano and Sandberg's article points to the importance of using the term "moral enhancement" in a sufficiently specified way. He asks how we are supposed to model or even think about a future in which agents can interact in ways we may not be able to imagine, and have values beyond our current comprehension and powers of action far beyond our understanding in a society structured along lines we are equally unable to fathom from our current perspective. Holm considers this question to pose a limitation to the argument advanced by Fabiano and Sandberg.

In contrast to the above-discussed articles, Johnny McDonald and Nicholas Agar do not focus on moral enhancement, but rather on enhancement in general. In "Transformative Change, Human Enhancement, and the Story of Job" they ask whether we should expect human enhancement to promote the interests of those who are subject to it. Their focus is on "transformative change": a change that significantly alters the value individuals place on their experiences or achievements. McDonald and Agar argue that what they call "too much enhancement" is a potential threat to many valuable things in our lives. For example, it jeopardizes our relationships with other humans. They use the case of Job as an illuminating example. Job lost all his children and property, but God blessed him with more property and objectively superior children (more beautiful and intelligent). Could new and enhanced offspring have made Job happier in light of the fact that he previously lost his earlier progeny, children who were not perfect but whom he loved? From his new perspective, the answer might be positive. But what if Job had been asked about the plan while his deceased children were still alive? Then the answer would almost certainly have been negative. There appears to be a temporal inconsistency in Job's evaluation of the change. This temporal inconsistency indicates the power of our relationships with other people and other contexts.

The orientation of Milan Ćirkovićis also on enhancement in general. In "Enhancing a Person, Enhancing a Civilization: A Research Program at the Intersection of Bioethics, Future Studies, and Astrobiology" he argues that it might appear paradoxical to consider bioethics and postbiological evolution in the same context. Nonetheless, Ćirković argues that is precisely what we need to do to elucidate the possibility of transition between biological and postbiological domains on Earth and elsewhere. Although the transition is obviously relatable to the issue of future human evolution, it is also relevant in wider contexts: animal psychology, artificial intelligence (AI) studies, the Search for Extra Terrestrial Intelligence (SETI) studies, as well as other studies of nonhuman intelligence. This transition has not been accompanied by a problematization of corresponding moral issues (at least not to the degree Milan Ćirković had hoped for).

All in all, this special section is one more indication that the interest in moral bioenhancement and other sorts of bioenhancements is continuing to increase. Much of this interest is directed to the ethical issues that bioenhancement raises. It testifies, therefore, to a continuation and augmentation of bioethics awareness among philosophers. The fact that the collection evoked ready reactions/commentaries even before its publication is one of the signs of this increased interest. The rapid development of neurosciences will only further strengthen this trend. We hope, therefore, to read similar collections in future issues of Cambridge Quarterly of Healthcare Ethics. 


\section{Guest Editorial}

\section{Notes}

1. Burton, RF (translator and annotator). The Book of the Thousand Nights and One Nights. The University of Adelaide, 2006 (originally published in 1886); available at https:/ /ebooks.adelaide. edu.au/b/burton/richard/b97b/complete.html\#section1 (last accessed 8 Dec 2016).

2. A book published by John Harris in 2016 has precisely this title. (Harris J. How to be Good. Oxford: Oxford University Press; 2016).

3. Doyle MW. Kant, liberal legacies and foreign affairs. Philosophy and Public Affairs 1983;12:205-35, 323-53.

4. Pinker S. The Better Angels of Our Nature. Penguin Books: London; 2011. 


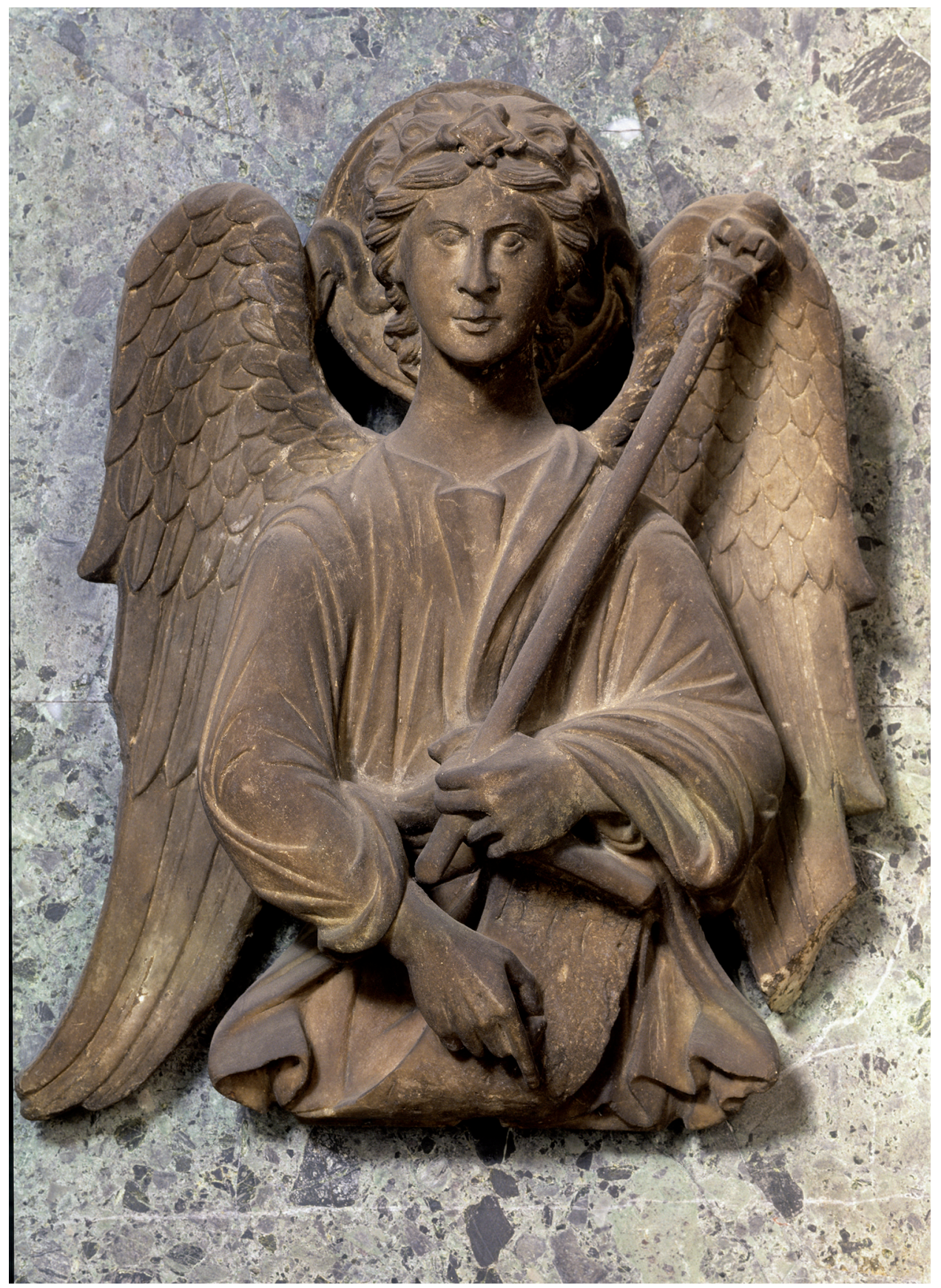

Anonymous, $18^{\text {th }}$ century, Relief of an Angel, Location: Baptistery, S. Marco, Venice, Italy, Photo Credit: Cameraphoto Arte, Venice/Art Resource, NY. Reproduced by permission. 